\title{
Celebrating the First Anniversary of IJGE
}

The year of 2015 was a significant year. It was the year that witnessed the debut of the International Journal of Geohazards and Environment (IJGE) - the world's first multidisciplinary international journal in the covered field. It was a year that was full of ambitions, excitements and challenges for all of us involved in the Journal. Prior to the inauguration, we made lots of plans for the Journal and were determined to make it an authoritative and high quality scientific journal in this field. When the Inaugural Issue eventually became live online in April 2015, joy and excitement filled the minds of everyone involved, seeing the results of over one-year's hard work in preparation from a number of dedicated volunteers. As the operation continued, we faced various challenges, and we tackled them all one by one. The year of 2015 was not an easy year but was a successful year for the Journal. In today's digital era, which is flooded with various types of online information and open access publishing, we made no compromise in quality and maintained high standards for the Journal. We are very proud of IJGE standing out in the crowd for its high quality and uniquely focused coverage.

April 2016 marks the first anniversary of the International Journal of Geohazards and Environment. Over the past year, four issues with high quality papers were successfully published as planned. This success of IJGE would not be possible without contributions of many people: the Editorial Board consisting of twenty one internationally known outstanding scholars, the valuable authors and reviewers, and the dedicated editors and staff in the IJGE office. I would like to thank them all for the time and efforts they contributed to the Journal.

Looking ahead, we see a bright future for the Journal with publication increased and high quality maintained. We will continue our efforts to increase its exposure and promote its awareness in the research and scientific communities. We will continue encouraging submissions of works in various aspects in the relevant fields. Built upon our success and experience in the past year, I am very confident that together, we will make the Journal successful next year and many years to come, and we will make a difference towards research of geohazards and protection of the associated environment.

D.H. Steve Zou, Ph.D., P. Eng.

Editor-in-Chief

April, 2016 